Produção e Caracterização Físico-Mecânica de Briquetes de Fibra de Coco e Palha de Cana-de-Açúcar

\author{
Padilla, E. R. D.;* Pires, I. C. S. A.; Yamaji, F. M.; Fandiño, J. M. M.
}

Rev. Virtual Quim., 2016, 8 (5), 1334-1346. Data de publicação na Web: 22 de agosto de 2016

http://rvq.sbq.org.br

\title{
Production and Physical-Mechanical Characterization of Briquettes from Coconut Fiber and Sugarcane Straw
}

\begin{abstract}
Biomass in a broad sense has a great energy potential. It can be densified improving the logistic and the energetic efficiency. The aim of the present work was the characterization of coconut fiber (FC) and sugarcane straw (PC) and the evaluation of mechanical properties of the briquettes produced from these materials. The samples of materials were performed to proximate analysis and high heating value (HHV) with three repetitions. Five different blends were tested with 15 repetitions for each blend: treatment T1 (100\% FC), T2 (75\% FC and 25\% PC), T3 (50\% FC and 50\% PC), T4 (25\% FC and 75\% PC) and T5 (100\% PC). It was used particles size smaller than $0.84 \mathrm{~mm}$ with $12 \%$ moisture content for the briquettes production. The process was done in a hydraulic press without heating or binder. Briquette length expansion at specific time intervals was determined over a 72 hours period. The strength and friability of briquettes were measured after the production period of six days. The results showed that in the proximate analysis and HHV coconut fiber and sugarcane straw presented $74.01 \%$ and $77.50 \%$ for volatile matter, $3.71 \%$ and $5.68 \%$ for ash, $22.28 \%$ and

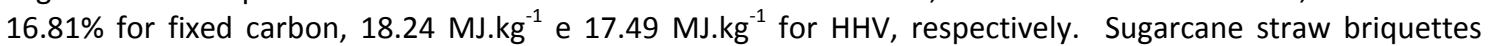
were classified as very crumbly. However, blending coconut fiber with sugarcane straw improved the quality of briquette.
\end{abstract}

Keywords: Biomass; bioenergy; mechanical strength; solid biofuel.

\section{Resumo}

A biomassa, em geral, mostra um grande potencial energético. Ainda na sua forma compactada pode melhorar a logística e a eficiência energética. Neste sentido o presente trabalho teve como objetivo caracterizar a fibra de coco (FC) e a palha de cana-de-açúcar (PC) e avaliar as propriedades mecânicas dos briquetes produzidos. A biomassa foi caracterizada em relação à analises química imediata e poder calorífico superior (PCS) com três repetições cada. Para a produção dos briquetes foram realizados cinco tratamentos com 15 repetições: tratamento T1 (100\% FC), T2 (75\% FC e 25\% PC), T3 (50\% FC e 50\% PC), T4 (25\% FC e 75\% PC) e T5 (100\% PC). Briquetes foram produzidos utilizando os materiais com granulometria inferior a $0.84 \mathrm{~mm}$ e teor de umidade de $12 \%$. Foi utilizada uma prensa hidráulica sem aquecimento e não houve adição de aglutinante. A expansão dos briquetes foi acompanhada durante as suas primeiras 72 horas. Após seis dias da produção, os briquetes foram submetidos aos testes de resistência mecânica. Os resultados na análise química imediata e PCS, mostraram que a fibra de coco e a palha da cana-de-açúcar apresentaram valores de $74.01 \%$ e $77.50 \%$ para voláteis, $3.71 \%$ e $5.68 \%$ para cinzas, $22.28 \%$ e $16.81 \%$ para carbono fixo, $18.24 \mathrm{MJ}^{.} \mathrm{kg}^{-1}$ e $17.49 \mathrm{MJ} . \mathrm{kg}^{-1}$ para o PCS, respectivamente. Briquetes de palha de cana-de-açúcar foram classificados como muito friáveis. No entanto, a adição de fibra de coco melhorou a qualidade dos briquetes.

Palavras-chave: Biomassa; bioenergia; resistência mecânica; biocombustível sólido.

\footnotetext{
* Universidade de Córdoba, Departamento de engenheira mecânica, Campus Montería, Carrera 6 No. 76-103, CP 230002, Montería, Córdoba, Colômbia.

Merdurango22@gmail.com DOI: $\underline{10.21577 / 1984-6835.20160095}$
} 


\section{Produção e Caracterização Físico-Mecânica de Briquetes de Fibra de Coco e Palha de Cana-de-Açúcar}

\section{Elias Ricardo D. Padilla, ${ }^{a}$ * Isis Cristina S. A. Pires, ${ }^{b}$ Fabio M. Yamaji, ${ }^{c}$ Jorge Mario M. Fandiño ${ }^{d}$}

a Universidade de Córdoba, Departamento de engenheira mecânica, Campus Montería, Carrera 6 No. 76-103, CP 230002, Montería, Córdoba, Colômbia.

${ }^{\mathrm{b}}$ Universidade Federal de São Carlos, Campus Sorocaba, Programa de Pós-Graduação em Ciência dos Materiais, Rod. João Leme dos Santos, Km 110, Bairro Itinga, CEP 18052-780, Sorocaba-SP, Brasil.

c Universidade Federal de São Carlos, Campus Sorocaba, Programa de Pós-Graduação em Planejamento e Uso de Recursos Renováveis, Rod. João Leme dos Santos, Km 110, Bairro Itinga, CEP 18052-780, Sorocaba-SP, Brasil.

'Universidade de Córdoba, Departamento de engenheira mecânica e Ambiental, Campus Montería, Carrera 6 No. 76-103, CP 230002, Montería, Córdoba, Colômbia.

* erdurango22@gmail.com

Recebido em 23 de outubro de 2015. Aceito para publicação em 15 de agosto de 2016

\section{Introdução}

\section{Materiais e Métodos}

2.1. Preparação e caracterização dos materiais

2.2. Confecção e teste dos briquetes

2.3. Análise estatística

\section{Resultados e Discussão}

3.1. Teor de umidade e granulometria

3.2. Análise imediata e poder calorífico superior (PCS)

3.3. Estabilidade dimensional

3.4. Resistência à compressão e friabilidade

\section{Conclusões}

\section{Introdução}

A sociedade mundial está mais consciente dos custos e riscos de manter uma matriz energética altamente dependente dos combustíveis fósseis. Assim, o mundo está buscando fontes de energia alternativas e renováveis. ${ }^{1}$ A biomassa é atualmente a principal fonte de energia em muitos países em desenvolvimento e, por diferentes razões, sejam elas ambientais ou socioeconômicas, 
também está crescendo em muitos países industrializados. $^{2}$

Neste cenário, surgem os biocombustíveis sólidos como uma maneira de tirar proveito da biomassa residual para produção de energia. Estes resíduos podem ser compactados, podendo apresentar uma redução de volume de cinco a dez vezes, dependendo do tipo de matéria-prima, gerando materiais de maior densidade e durabilidade, classificados como briquetes. ${ }^{3}$ Esse processo, além de melhorar a estocagem, pode facilitar o transporte e manipulação da biomassa, devido ao formato homogêneo dos briquetes. ${ }^{3}$

Os principais resíduos da cana-de-açúcar são a palha, constituída por ponteiros e folhas, seguido pelo bagaço. A queima da palha da cana-de-açúcar antes da colheita era uma prática comum para aumentar o rendimento da colheita manual. No entanto, esta prática não é mais aceita, sendo substituída pela colheita mecanizada. ${ }^{4}$

No Brasil, existe um grande potencial para a produção de briquetes e pellets. ${ }^{5}$ Para a safra 2015/2016, o Brasil produziu 665,6 milhões de toneladas de cana-de-açúcar, das quais 367,6 milhões de toneladas foram produzidas no estado de São Paulo. ${ }^{6}$ Considerando-se que cada tonelada de canade-açúcar colhida possui em torno de $140 \mathrm{~kg}$ de palha, ${ }^{7}$ assim, cerca de 93,19 milhões de toneladas foram geradas nessa safra.

Outro resíduo considerado de grande volume vem do coco verde. Aproximadamente de $80 \%$ a $85 \%$ do peso bruto do coco verde é representado pelas cascas. ${ }^{8}$ No ano 2014 , a quantidade de coco verde destinada para produção de água de coco foi de 1,5 bilhão, os quais geraram cerca de 2.227 mil toneladas de resíduos, estima-se que $70 \%$ de todos os resíduos gerados nas praias brasileiras sejam cascas de coco verde. $^{9}$

A caracterização química e energética dos resíduos de coco e da palha de cana-deaçúcar é importante para determinar a viabilidade da produção de biocombustíveis a partir de diferentes matérias-primas. ${ }^{10} \mathrm{~A}$ análise química imediata e a determinação de poder calorífico são métodos muito usados para este fim. ${ }^{11} \mathrm{O}$ teor de umidade desempenha um papel importante, porque determina a facilidade de compactação da biomassa e influencia a estabilidade e durabilidade dos briquetes. ${ }^{3}$

O teste de expansão busca avaliar a estabilidade dimensional dos briquetes após a produção e pode definir o tempo mínimo de espera após a briquetagem, para a realização do ensaio de tração por compressão diametral e tamboramento. ${ }^{12} \mathrm{O}$ ensaio de tração por compressão diametral determina a resistência à compressão para corpos de prova cilíndricos. Com os resultados pode-se calcular também a altura máxima de empilhamento na estocagem. ${ }^{13} \mathrm{O}$ teste de tamboramento determina o índice de friabilidade ou abrasão, provocada durante o transporte ou manuseio dos briquetes. ${ }^{14}$

Todos estes testes são usualmente os mais empregados para medir a qualidade dos briquetes, no entanto, os resultados devem ser interpretados com cuidado, porque são influenciados pelas características dos materiais e pelo tamanho e forma dos briquetes. ${ }^{14}$

O presente trabalho teve como objetivo caracterizar a fibra de coco e a palha de canade-açúcar mediante a análise química imediata e a determinação do poder calorifico superior (PCS) além de avaliar a qualidade mecânica dos briquetes produzidos.

\section{Materiais e Métodos}

\subsection{Preparação e caracterização dos materiais}

A casca de coco verde e a palha de canade-açúcar foram coletadas na cidade de Sorocaba-SP e na fazenda Corredeira em Ibaté-SP, Brasil, respectivamente. Inicialmente, foi determinado o teor de 
umidade dos materiais conforme a norma ASTM E870-13. ${ }^{15}$ Todos os materiais foram secados em estufa com circulação de ar marca Marconi MA-35, para depois passar pelo moinho de facas tipo Willey (Marconi MA-340). Em seguida, análise granulométrica foi realizada para obter a distribuição do tamanho das partículas de cada material.

A classificação das partículas foi realizada pelo método de análise por peneiras padronizadas de acordo com a norma ABNT NBR NM 248/2003, ${ }^{16}$ utilizando um peneirador vibratório orbital marca Maroni MA-75 e um conjunto de peneiras com aberturas de 0,$84 ; 0,42 ; 0,25$ e $0,15 \mathrm{~mm}$ (20, $40,60,100$ mesh). Cada teste foi feito com 100,00 gramas de material e um tempo de vibração de 3 min.

$\mathrm{Na}$ análise química imediata foi determinado o teor de voláteis e o teor de cinzas para a fibra de coco e a palha da cana- de-açúcar conforme a norma ASTM E870$13,{ }^{15}$ com três repetições para cada teste. 0 valor de carbono fixo foi calculado pela diferença.

O poder calorífico superior (PCS) foi determinado de acordo com a norma ASTM E870-13, ${ }^{15}$ utilizando-se uma bomba calorimétrica marca IKA modelo C200, com três repetições para cada tratamento.

\subsection{Confecção e teste dos briquetes}

Para fabricar os briquetes, o teor de umidade dos materiais foi corrigido para $12 \%$ com auxílio de um borrifador de água. Para comprovar o teor de umidade foi utilizada uma balança determinadora de umidade marca Marconi ID 200. Foram realizados 5 tratamentos com 15 repetições para cada tratamento, como mostra a tabela 1.

Tabela 1. Tratamentos para produção de briquetes

\begin{tabular}{ccc}
\hline Tratamento & $\begin{array}{c}\text { Fibra de coco } \\
(\%)\end{array}$ & $\begin{array}{c}\text { Palha de cana- } \\
\text { de-açúcar (\%) }\end{array}$ \\
\hline T1 & 100 & 0 \\
T2 & 75 & 25 \\
T3 & 50 & 50 \\
T4 & 25 & 75 \\
T5 & 0 & 100 \\
\hline
\end{tabular}

Cada briquete foi confeccionado utilizando-se $20,00 \mathrm{~g}$ de material com tamanho de partícula inferior a $0,84 \mathrm{~mm}$, mantendo uma pressão de $122,31 \mathrm{MPa}$ por 30 s, sem aquecimento e sem adição de aglutinante. A produção foi realizada em uma prensa hidráulica marca Marconi MPH-30 com o auxílio de moldes cilíndricos de 35,00 $\mathrm{mm}$ de diâmetro e 160,00 mm de altura, seguindo o mesmo procedimento usado por Hansted. ${ }^{17}$

Após a briquetagem, as dimensões no sentido longitudinal foram medidas em todos os briquetes com auxílio de um paquímetro digital com precisão de $0,01 \mathrm{~mm}$. As mensurações repetiram-se em intervalos determinados de 1, 2, 4, 6, 12, 24, 48 e 72 horas, a fim de acompanhar a expansão longitudinal dos briquetes. ${ }^{17}$ As condições de armazenamento e o tipo de biomassa influenciam no comportamento de expansão após a briquetagem ${ }^{3}$. Os briquetes foram armazenados em ambiente controlado para que não houvesse alteração do teor de umidade devido aos fatores externos. $O$ teste de expansão foi realizado para avaliar a estabilidade dimensional dos briquetes armazenados nas condições de $65 \%$ umidade relativa e temperatura de $21,1{ }^{\circ} \mathrm{C}$ (umidade de equilíbrio de $12 \%$ ).

Após seis dias da produção dos briquetes foi realizado o ensaio de tração por 
compressão diametral e a última medição longitudinal dos briquetes. $O$ ensaio de tração por compressão diametral foi feito de acordo com a norma ABNT NBR $7222,{ }^{18} \mathrm{com}$ auxílio da máquina universal de ensaios (EMIC - modelo DL30000), e assistência de uma célula de carga de 4,9 kN. Foram utilizadas 10 repetições para cada tratamento e os resultados foram obtidos diretamente pelo programa Tesc versão 3.04 do equipamento. Com os resultados do ensaio foi calculada a altura máxima de empilhamento para cada tratamento, seguindo o mesmo procedimento de Silva e colaboradores. ${ }^{12}$

No teste de tamboramento foram ensaiados cinco briquetes de cada tratamento em um friabilômetro, com rotação de $34 \mathrm{rpm}$, durante 15 minutos. Ao fim do teste, separou-se com uma peneira de $0,84 \mathrm{~mm}$ (20 mesh) a massa que se desprendeu dos corpos de prova, e foi calculado o índice de friabilidade conforme a norma ABNT NBR $8740 .{ }^{19}$

\subsection{Análise estatística}

As análises estatísticas foram realizadas com assistência do programa Statgraphics versão 15.2.05 e Excel 2013.

Foi aplicado o teste de Bartlett para verificar homogeneidade das amostras (variância). Quando o resultado de p-valor foi menor que o nível de significância, constatou- se que as amostras apresentaram diferenças estatísticas significativas entre os desvios padrão. Quando não houve diferença estatística significativa entre os desvios padrão, continuou-se com as demais análises estatísticas.

Foram verificadas as diferenças na variância pelo método da ANOVA, onde foi possível constatar se houve diferença estatística entre as médias. Quando o resultado de $p$-valor foi menor que o nível de significância, constatou- se que as amostras apresentaram diferenças estatísticas significativas entre as médias.
Quando os resultados da ANOVA apresentaram valores menores que o nível de significância usado, os tratamentos foram analisados pelo método de comparação de médias Tukey para verificar qual tratamento foi significativamente diferente dos outros.

Para todas as análises foi considerado o nível de confiança de $95 \%(\alpha=0,05)$.

\section{Resultados e Discussão}

O método de Bartlett mostrou que não houve diferença estatisticamente significativa entre os desvios-padrão, de todas as repetições, para todos os testes realizados.

\subsection{Teor de umidade e granulometria}

A partir dos dados obtidos experimentalmente, foi calculado o teor de umidade inicial dos materiais em base úmida. Os resultados mostraram que a palha da cana-de-açúcar e a fibra de coco tinham teor de umidade de $10,4 \%$ e $85,8 \%$, respetivamente. A casca do coco verde, apresenta umidade entre $80 \%$ a $85 \%$, o que inviabiliza a utilização para queima e altera a estabilidade e a resistência mecânica dos briquetes..$^{20-21} \mathrm{~A}$ secagem ao sol de cascas de coco verde durante, aproximadamente, quatro dias, pode reduzir a umidade inicial de $85 \%$ para valores em torno de $15 \%$ a $20 \%{ }^{8}$

A palha de cana-de-açúcar se encontrava estocada ao ar livre, isto explica a baixa umidade da palha de cana-de-açúcar. $\mathrm{Na}$ literatura, foram encontrados valores entre 8,42 e $13,5 \%$ de o teor de umidade da palha de cana-de-açúcar. ${ }^{22}$

Hansted, ${ }^{21}$ produziu briquetes com três diferentes teores de umidade, e encontrou que $12 \%$ de umidade foi o melhor ajuste para a formação dos briquetes. São preferidas biomassas para briquetagem com teor de umidade entre $10 \%$ e $15 \% .{ }^{13,23}$ Portanto, o teor de umidade para todos os tratamentos foi corrigido para $12 \%$ de umidade. 
$\mathrm{Na}$ classificação granulométrica, foram obtidos os resultados mostrados na Figura 1. Pode ser observado que a distribuição do tamanho da partícula obtida para a fibra de coco, apresentou comportamento uniforme.
Observou-se também que $81,57 \%$ da palha de cana-de-açúcar analisada apresentou granulometria maior que $0,42 \mathrm{~mm}$ (40 mesh), com a maior concentração de partículas retidas na peneira de $0,42 \mathrm{~mm}$ (40 mesh).

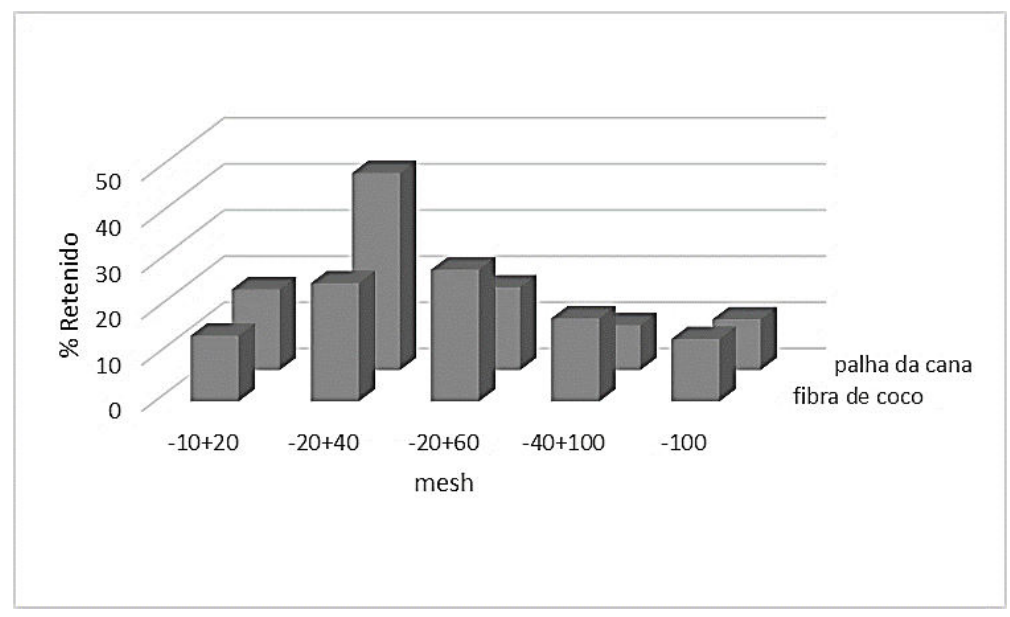

Figura 1. Classificação granulométrica da biomassa

A granulometria pode influenciar na formação e resistência mecânica dos briquetes. ${ }^{24}$ Gonçalves, ${ }^{25}$ produziu briquetes variando a granulometria, encontrou que foi possível a formação de briquetes em todos os tratamentos estudados, mas o tratamento de $0,84 \mathrm{~mm}$ a $0,15 \mathrm{~mm}$ apresentou os melhores valores de resistência à compressão. A compactação pode ser otimizada utilizando diferentes tamanhos de partículas, o que aumenta a ligação e produz briquetes de ótima qualidade. ${ }^{13}$ Neste trabalho, para a fabricação dos briquetes foram utilizadas partículas menores que $0,84 \mathrm{~mm}$ (20 mesh).

\subsection{Análise química imediata e poder calorífico superior (PCS)}

Os resultados da análise química imediata e o PCS dos tratamentos estão apresentados na Tabela 2.

Tabela 2. Análises química imediata (base seca)

\begin{tabular}{ccccc}
\hline Tratamento & $\begin{array}{c}\text { Voláteis } \\
(\%)\end{array}$ & $\begin{array}{c}\text { Cinzas } \\
(\%)\end{array}$ & $\begin{array}{c}\text { Carbono } \\
\text { fixo (\%) }\end{array}$ & $\begin{array}{c}\text { PCS } \\
\left(\mathrm{MJ} . k g^{-1}\right)\end{array}$ \\
\hline T1 & 74,01 & 3,71 & 22,28 & 18,24 \\
T5 & 77,50 & 5,68 & 16,81 & 17,49 \\
\hline
\end{tabular}

Os voláteis têm um papel importante durante as etapas iniciais da combustão. ${ }^{11} \mathrm{~A}$ biomassa geralmente tem alto teor de voláteis. ${ }^{26}$ Como observado na tabela 2 , os voláteis representaram a maior fração dos constituintes da fibra de coco e da palha de cana-de-açúcar (T1 e T5). Para ambos os materiais o teor de voláteis foi semelhante.

Com relação ao teor de cinzas, a palha de cana-de-açúcar apresentou 5,68\%. Esse valor 
é considerado alto, pois para briquetagem é recomendado um teor de cinzas menor que $4 \%$, valores superiores podem causar corrosão no equipamento. ${ }^{23} \mathrm{~A}$ maior quantidade de cinzas na palha de cana-deaçúcar pode ser explicada por uma possível contaminação das amostras. Após a colheita a palha fica depositada no campo. Depois é feito o enleiramento e o enfardamento com equipamentos que coletam a palha diretamente do solo.

O elevado teor de cinzas encontrado na palha de cana-de-açúcar e o elevado teor de umidade da fibra de coco, além de dificultar a briquetagem também podem causar problemas na ignição e combustão. ${ }^{26}$

O principal constituinte da biomassa para combustíveis é o carbono. ${ }^{27} \mathrm{Na}$ análise química imediata, o maior teor de carbono fixo indica maior quantidade de massa orgânica rica em carbono, entretanto, quando o teor de cinzas aumenta, a fração orgânica diminui. ${ }^{28}$ Portanto, os resultados mostraram que o teor de carbono fixo calculado, foi menor para a palha de cana-deaçúcar comparada à fibra de coco.

Na literatura, encontrou-se que a fibra de coco e palha de cana-de-açúcar possuem valores de $77,00 \%$ e $86,64 \%$ para teor de voláteis, $2,96 \%$ e $3,85 \%$ para cinza, $20,05 \%$ e $9,51 \%$ carbono fixo, respectivamente. ${ }^{22,27}$ Pode-se notar que alguns resultados encontrados nesse estudo foram similares aos valores de referência.

Quanto ao PCS, os resultados dos tratamentos estudados são mostrados na figura 2.

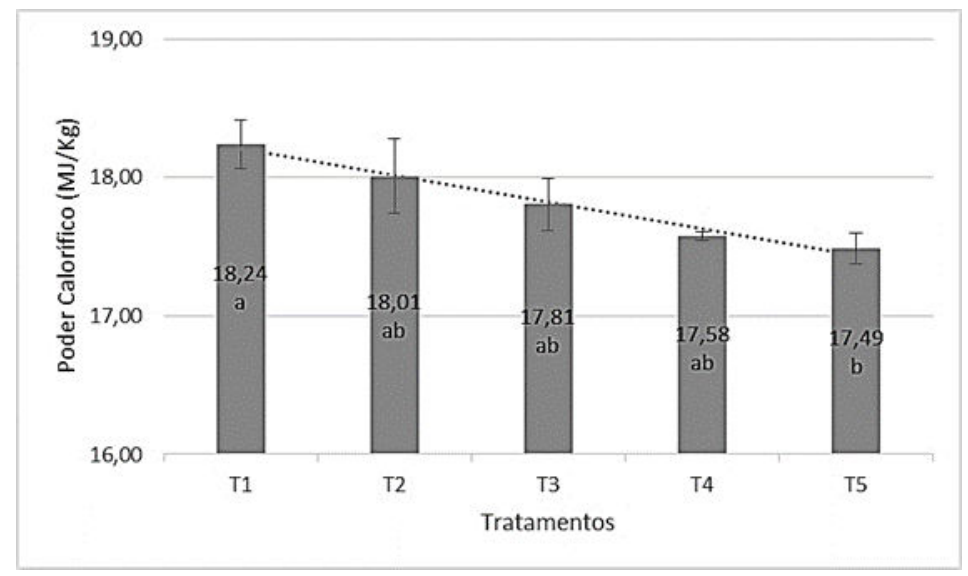

Figura 2. Poder calorífico médio do tratamento (base seca). Médias seguidas da mesma letra não diferem estatisticamente entre si, ao nível de $5 \%$ de erro no teste Tukey

O valor obtido para a fibra de coco e palha de cana-de-açúcar (T1 e T5) foi de 18,24 MJ.kg ${ }^{-1}$ e 17,49 MJ.kg ${ }^{-1}$, respectivamente. Os resultados do PCS foram semelhantes aos encontrados na literatura, de $18,70 \mathrm{MJ} \cdot \mathrm{kg}^{-1}$ para a fibra de coco e $17,40 \mathrm{MJ}^{\mathrm{kg}} \mathrm{k}^{-1}$ para a palha de cana-de-açúcar. ${ }^{22,27}$ Observou-se que o PCS nas misturas decresceu linearmente ao mesmo tempo que a percentagem de palha de cana-de-açúcar aumentou. $\mathrm{O}$ alto desvio padrão observado pode ser devido à biomassa ser um material heterogêneo.
O PCS da biomassa pode ser correlacionado com os resultados da análise química imediata. Em geral, o PCS aumenta com o aumento do teor de carbono fixo e diminui com o aumento do teor de cinza. ${ }^{29-30}$ Cada aumento de $1 \%$ no teor de carbono fixo eleva o PCS 0,39 MJ. $\mathrm{kg}^{-1}$, e com cada aumento de $1 \%$ no teor de cinzas o PCS diminui em 0,2 MJ. $\mathrm{kg}^{-1} .{ }^{26}$ Portanto, o maior PCS encontrado na fibra de coco pode ser explicado pelo maior teor de carbono fixo e menor teor de cinzas comparado à palha de cana-de-açúcar. 
Houve diferença estatisticamente significativa entre a média de T1 e T5. Os demais tratamentos não diferiram estatisticamente entre si, indicando que o PCS nas misturas (T2, T3, T4) não variou significativamente com a mudança na proporção dos materiais.

\subsection{Estabilidade dimensional}

A Figura 3 mostra que os briquetes obtiveram formação satisfatória, sem aquecimento e sem adição de aglutinante.

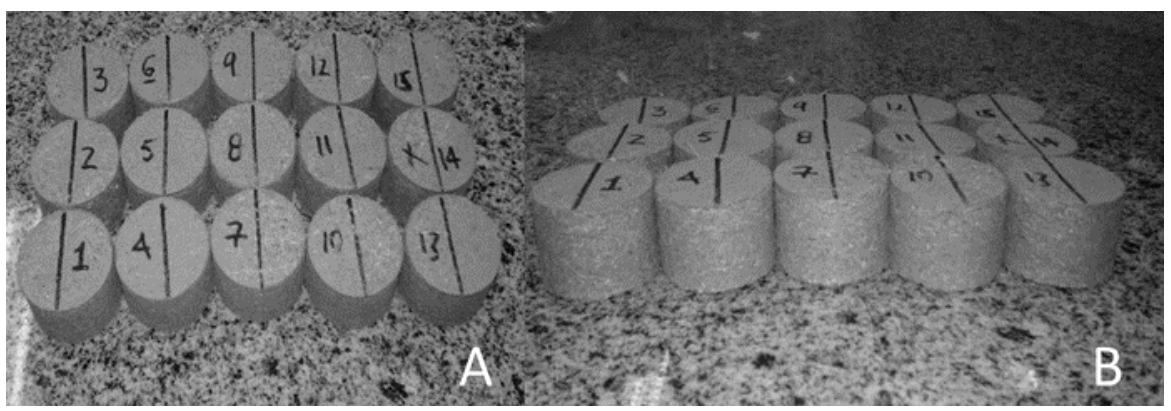

Figura 3. Briquetes do tratamento T3 após briquetagem. Vista de topo (A), Vista lateral (B)

Os resultados (Figura 4) mostraram que todos os tratamentos expandiram rapidamente logo depois da liberação da pressão. Este resultado é consistente com o estudo de Mohsenin e Zaske, ${ }^{31}$ que afirmam que após a briquetagem o aumento da expansão nos briquetes é logarítmica até um período de 2 horas.

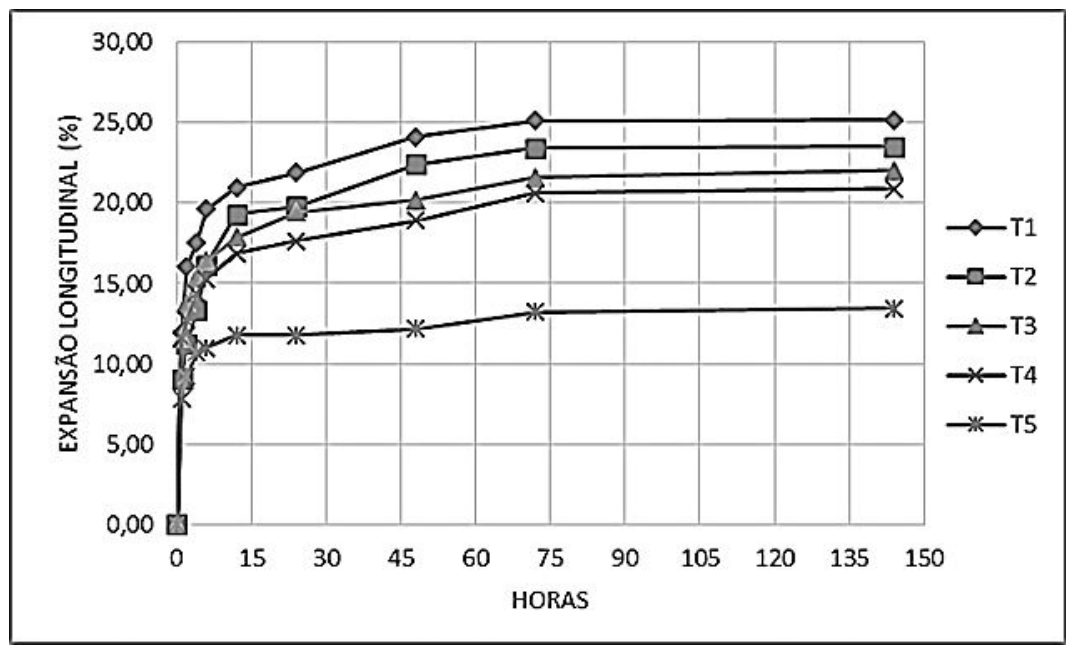

Figura 4. Expansão longitudinal média do tratamento

O tratamento T1 exibiu a maior expansão de 25,17\%, enquanto T5 apresentou a menor expansão de $13,47 \%$. Observou-se que nas misturas, com o aumento da palha de canade-açúcar a expansão dos briquetes reduziu.
Os resultados de outros estudos indicam que briquetes quando submetidos as condições de $20^{\circ} \mathrm{C}$ e $95 \%$ de umidade relativa durante 21 dias, uma expansão inferior a 30\% foi aceitável e menos de $20 \%$ considerou-se ideal. $^{32} \mathrm{O}$ tratamento T1 apresentou uma expansão considerada aceitável. O aumento 
da proporção de palha de cana-de-açúcar de $0 \%$ para $75 \%$ reduziu a expansão de $25,17 \%$ para $20,90 \%$, conseguindo atingir uma expansão próxima à ideal.

Houve diferença estatisticamente significativa entre a média de T5 e as médias dos demais tratamentos. Entretanto, os tratamentos T1, T2, T3 e T4 não diferiram estatisticamente entre si, indicando que a redução da expansão apresentada nesses tratamentos não foi significativa com as diferentes proporções dos materiais.

Para ser representativo, os ensaios mecânicos devem ser realizados após os briquetes atingirem a estabilidade dimensional, assim o teste de expansão também é importante porque pode definir o tempo mínimo de espera após a briquetagem, para a realização do ensaio de tração por compressão diametral e friabilidade. ${ }^{12} \mathrm{Na}$ figura 4 , pode ser observado que todos os briquetes apresentaram estabilidade dimensional 72 horas após ser produzidos. Em geral, a maior expansão ocorre no sentido longitudinal durante as primeiras 24 horas após a briquetagem, depois de uma semana é atingida a estabilidade dimensional. ${ }^{33}$ Estudos indicam que a expansão radial varia de $2 \%$ a $5 \%{ }^{31}$

\subsection{Resistência à compressão e friabilidade}

A resistência à compressão para corpos de prova cilíndricos pode ser interpretada como a força de ligação interna ou a força máxima que pode suportar um corpo (briquetes) antes da ruptura durante 0 armazenamento. ${ }^{34} \mathrm{Na}$ Tabela 3 encontram-se os resultados do ensaio de tração por compressão diametral.

Tabela 3. Dados do ensaio de resistência à compressão diametral e altura máxima de empilhamento calculada

\begin{tabular}{cccc}
\hline Tratamentos & $\begin{array}{c}\text { Força } \\
\text { Máxima } \\
\text { (N) }\end{array}$ & $\begin{array}{c}\text { Resistência } \\
\text { Máxima } \\
\text { (MPa) }\end{array}$ & $\begin{array}{c}\text { Altura } \\
\text { Máxima de } \\
\text { Empilhamento } \\
(\mathrm{m})\end{array}$ \\
\hline T1 & $459,26 \mathrm{a}$ & $0,37 \mathrm{a}$ & 27,31 \\
T2 & $306,45 \mathrm{~b}$ & $0,23 \mathrm{~b}$ & 18,22 \\
T3 & $269,01 \mathrm{c}$ & $0,19 \mathrm{c}$ & 15,99 \\
T4 & $271,50 \mathrm{c}$ & $0,19 \mathrm{c}$ & 16,14 \\
T5 & $315,93 \mathrm{~b}$ & $0,24 \mathrm{~b}$ & 18,78 \\
\hline
\end{tabular}

Médias seguidas da mesma letra, na coluna, não diferem estatisticamente entre si, ao nível de $5 \%$ de erro no teste Tukey.

Embora o tratamento T1 tenha apresentado a maior expansão entre os cinco tratamentos, foi o tratamento que obteve a maior resistência mecânica $(0,37 \mathrm{MPa})$. Este comportamento foi semelhante ao encontrado por Silva, ${ }^{12}$ em briquetes de eucalipto, mostrando que em briquetes produzidos a partir de fibra de coco, a expansão longitudinal pode ser considerada normal e não afeta a qualidade dos briquetes.

A Figura 5 mostra os comportamentos tensão-deformação para os corpos de prova de todos os tratamentos. O limite de resistência à compressão é a tensão no ponto máximo na curva. ${ }^{35}$

Segundo os dados da Tabela 3, o tratamento T3 apresentou a menor resistência à compressão e, portanto, a altura máxima de empilhamento foi mais baixa entre os tratamentos. Entretanto, o valor da 
altura máxima calculado para T3 pode ser considerado um resultado aceitável, pois um galpão para armazenamento geralmente tem altura entre 10 e 15 metros livres desde o piso até o teto. ${ }^{36}$

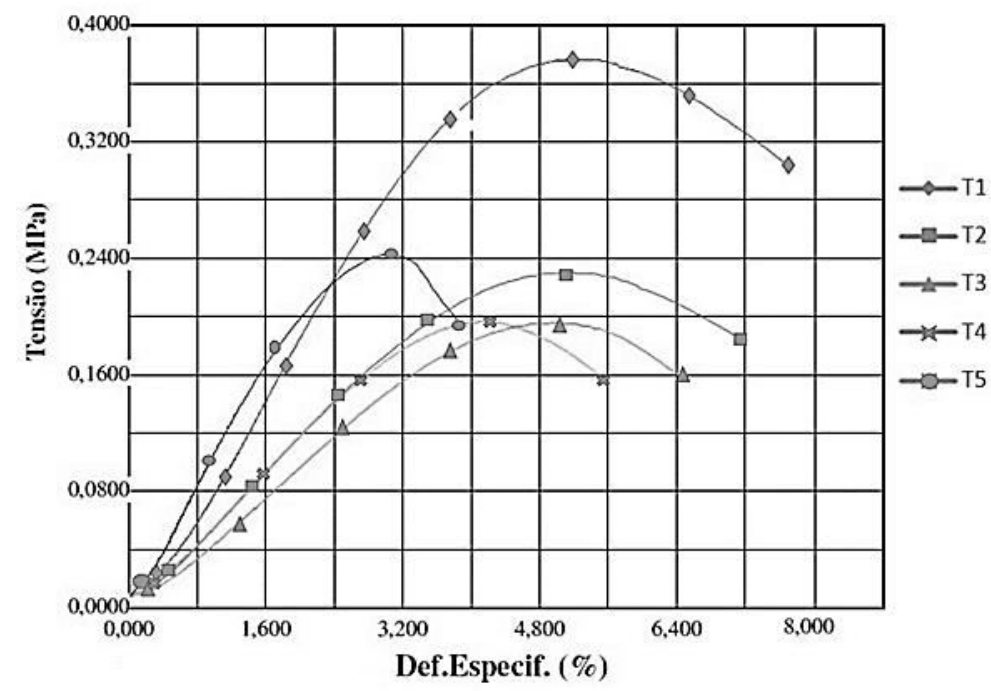

Figura 5. Comportamento tensão-deformação média para os briquetes de prova

Foi constatado por Silva e colaboradores, ${ }^{12}$ que uma altura máxima de empilhamento superiores a $10 \mathrm{~m}$ seria o suficiente para estocagem, no mesmo trabalho, briquetes feitos de palha de canade-açúcar tiveram resistência máxima de 0,97 MPa e altura máxima de estocagem de $59 \mathrm{~m}$. Portanto, a fibra de coco e a palha de cana-de-açúcar podem ser utilizadas para produzir briquetes com resistência à compressão satisfatória.
Como complemento aos resultados de resistência à tração por compressão diametral, o ensaio de tamboramento é um bom método para prever o comportamento dos briquetes durante sua cadeia de fornecimento (ou seja, da indústria de produção até o consumidor final). Portanto, a friabilidade pode ser interpretada como a capacidade dos briquetes para resistir ao manuseio e transporte. ${ }^{34} \mathrm{~A}$ Figura 6 mostra os resultados do ensaio de tamboramento.

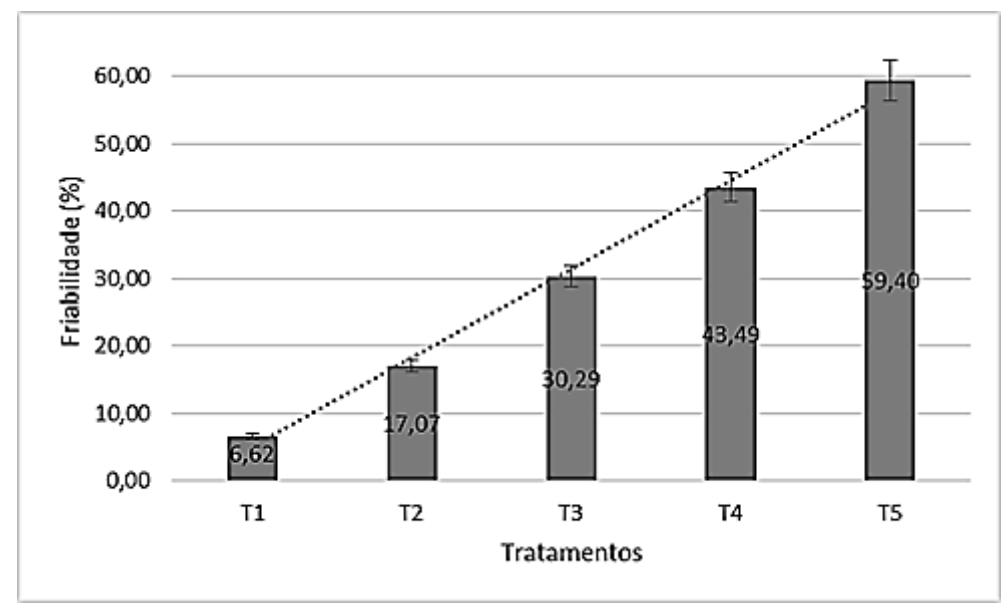

Figura 6. Índice de friabilidade média dos tratamento 
Observou-se que a friabilidade entre os tratamentos aumentou linearmente. O aumento foi proporcional ao aumento da percentagem de palha de cana-de-açúcar. 0 tratamento T1 apresentou o menor teor de friabilidade. De acordo com a classificação sugerida por Oliveira ${ }^{37}$ o tratamento T1 pode ser classificado como muito pouco friável (ou mais resistente). Em contrapartida, o tratamento T5 pode ser classificado como muito friável. Portanto, pode-se afirmar que misturar fibra de coco com palha de cana-deaçúcar ajudou a reduzir os finos gerados durante o manuseio dos briquetes.

Nesse contexto, o maior teor de fibra de coco utilizada nas misturas diminuiu a friabilidade, aumentou a altura máxima de empilhamento e aumentou o poder calorifico superior, porém, aumentou também a expansão longitudinal dos briquetes.

\section{Conclusões}

Pode-se concluir que a fibra de coco e palha de cana-de-açúcar podem ser utilizados na fabricação de briquetes sem adição de aglutinante e sem aquecimento durante a briquetagem. Todos os tratamentos obtiveram formação satisfatória, utilizando materiais com granulometria inferior a 0,84 $\mathrm{mm}$ e teor de umidade $12 \%$.

Nas características energéticas, a fibra de coco apresentou o maior PCS, maior teor de carbono fixo e menor teor de cinzas comparado à palha de cana-de-açúcar.

Todos os tratamentos apresentaram estabilidade dimensional 72 horas após serem produzidos e obtiveram altura máxima de empilhamento aceitável.

O aumento da fibra de coco nas misturas contribuiu para a redução dos finos gerados durante o teste de tamboramento.

Todos os tratamentos apresentaram uma altura calculada máxima de empilhamento considerada aceitável para estocagem.

\section{Agradecimentos}

O autor principal agradece $\mathrm{O}$ apoio concedido pelo CNPq, a Universidade de Córdoba-Colômbia e ao grupo de pesquisa Biomassa Bioenergia da UFSCar-campus Sorocaba para a realização do presente trabalho.

\section{Referências Bibliográficas}

${ }^{1}$ Gazzoni, D. L.; Azurdia, I.; Blanco, G.; Estrada, C. A.; Macedo, I. C. Energía sustentable en América Latina y El Caribe: potencial para el futuro. Ciencia para una vida mejor: desarrollando programas científicos regionales en áreas prioritarias para América Latina y El Caribe 2010, 3, 114. [Link]

${ }^{2}$ Hackenberg, N. Biocombustibles de segunda generación. Revista Virtual REDESMA 2008, 2, 49. [Link]

${ }^{3}$ Yamaji, F. M.; Vendrasco, L.; Chrisostomo, W.; Flores, W. P. Análise do comportamento higroscópico de briquetes. Energia na Agricultura 2013, 28, 11. [CrossRef]

${ }^{4}$ Rosillo-Calle, F. Em Uso da biomassa para produção de energia na indústria brasileira; Braunbeck, O., Cortez, L. Editora da UNICAMP: Campinas, 2005, cap. 5. [Link]

${ }^{5}$ Yamaji, F. M.; Chrisostomo, W.; Vendrasco, L.; de Paula Flores, W. The use of forest residues for pellets and briquettes production in Brazil. Proceedings of Third International Symposium on Energy from Biomass and Waste, Venice, 2010.

${ }^{6}$ Conab. Acompanhamento da safra brasileira cana-de-açúcar safra 2015/16; Relatório Técnico. Brasília, 2016. [Link]

${ }^{7}$ Hassuani, S. J.; Leal, M. R. L. V.; Macedo, I.; Biomass power generation: Sugar cane bagasse and trash, 1a. ed., Published by Programa das Nações Unidas para o Desenvolvimento and Centro de Tecnologia Canavieira: Piracicaba, Brazil, 2005. [Link]

${ }^{8}$ Rosa, M. F; Santos, F. J. S.; Montenegro, A. A. T.; Abreu, F. A. P.; Correia, D; Araujo, F. B. S.; Norôes, E. R. V. Caracterização do pó da 
casca de coco verde usado como substrato agrícola. Embrapa Agroindústria Tropical, Comunicado Técnico 2001, 54, 6. [Link]

${ }^{9}$ Collares, D.; Paula, S. Propostas para o aproveitamento do potencial energético da casca do coco-verde. Informativo da Embrapa - Agroenergetico 2015, 63, 8. [Link]

${ }^{10}$ Naik, S., Goud, V. V., Rout, P. K., Jacobson, K., Dalai, A. K. Characterization of Canadian biomass for alternative renewable biofuel. Renewable Energy 2010, 35, 1625. [CrossRef] ${ }^{11}$ Cortez, L. Em Biomassa para energia; Cortez, L.; Lora, E.; Gomez, E. Editora da UNICAMP: Campinas, 2008, cap. 2.

${ }^{12}$ Silva, D. A.; Yamaji, F. M.; Barros, J. L.; Rós, A. L.; Nakashima, G. T. Caracterização de biomassas para a briquetagem. Floresta 2015, 45, 713. [CrossRef]

${ }^{13}$ Kaliyan, N; Morey, R. V. Factors affecting strength and durability of densified biomass products. Biomass and Bioenergy 2009, 33, 342. [CrossRef]

${ }^{14}$ Quirino, W. F.; Brito, J. O.; Dissertação de Mestrado, Universidade de São Paulo, 1991. [Link]

${ }^{15}$ ASTM E870-82, Standard Test Methods for Analysis of Wood Fuels, ASTM International, West Conshohocken, PA, 2013. [CrossRef]

${ }^{16}$ ABNT NBR 248, Agregados-Determinação da composição granulométrica, Associação Brasileira de Normas Técnicas: Rio de Janeiro, 2003. [Link]

${ }^{17}$ Hansted, A. L. S.; Nakashima, G. T.; Martins, M. P.; Yamamoto, H.; Yamaji, F. M. Comparative analyses of fast growing species in different moisture content for high quality solid fuel production. Fuel 2016, 184, 180. [CrossRef]

${ }^{18}$ ABNT NBR 7222, Concreto e argamassaDeterminação da resistência à tração por compressão diametral de corpos-de-prova cilíndricos, Associação Brasileira de Normas Técnicas: Rio de Janeiro, 2011. [Link]

${ }^{19}$ ABNT NBR 8740, Carvão vegetalDeterminação do índice de quebra e abrasão, Associação Brasileira de Normas Técnicas: Rio de Janeiro, 1985. [Link]

${ }^{20}$ Rocha, A. M.; Silva, M. S.; Fernandes, F. M.; Soares, P. M.; Konish, F. Aproveitamento de fibra de coco para fins energéticos: revisão e perspectivas. Anais do 10 Congresso sobre Geração Distribuída e Energia no Meio Rural, São Paulo, 2015. [Link]

${ }^{21}$ Hansted, A. L. S.; Nakashima, G. T.; Martins, M. P.; Yamaji, F. M. Caracterização físico-química da biomassa de Leucaena leucocephala para produção de combustível sólido. Revista Virtual de Química 2016, 8, 1449. [CrossRef]

${ }^{22}$ Rueda-Ordóñez, Y. J.; Tannous, K. Isoconversional kinetic study of the thermal decomposition of sugarcane straw for thermal conversion processes. Bioresource technology 2015, 196, 139. [CrossRef]

${ }^{23}$ Tripathi, A. K.; Iyer, P. V. R.; Kandpal, T. C. A. Techno-economic evaluation of biomass briquetting in India. Biomass and Bioenergy 1998, 14, 479. [CrossRef]

${ }^{24}$ Ribeiro, C. D.; Yamaji, F. M.; Vendrasco, L.; Flores, W. De P.; Chrisostomo, W. Efeito da granulometria nas propriedades físicomecânico de briquetes de pinus SP. Anais do $\checkmark$ Congresso Internacional de Bioenergia, Curitiba, 2010. [Link]

${ }^{25}$ Gonçalves, F. B.; Yamaji, F. M.; Fernandez, B. O.; Róz, A. L.; Floriano, F. S. Caracterização e comparação entre diferentes granulometrias de serragem de Eucalyptus grandis para confecção de briquetes. Revista Instituto Florestal 2013, 25, 205. [Link]

${ }^{26}$ Demirbas, A. Combustion characteristics of different biomass fuels. Progress in Energy and Combustion Science 2004, 30, 222. [CrossRef]

${ }^{27}$ Rambo, M. K. D.; Schmidt, F. L.; Ferreira, M. M. C. Analysis of the lignocellulosic components of biomass residues for biorefinery opportunities. Talanta 2015, 144, 699. [CrossRef]

2828 Jenkins, B.; Baxter, L. L.; Miles, T. R. Combustion properties of biomass. Fuel Processing Technology 1998, 54, 19. [CrossRef]

${ }^{29}$ Protásio, T. P.; Bufalino, L.; Tonoli, G. H. D.; Couto, A. M.; Trugilho, P. F.; Guimarães Júnior, M. Relação entre o poder calorífico superior e os componentes elementares e minerais da biomassa vegetal. Pesquisa Florestal Brasileira 2011, 31, 117. [CrossRef] 
${ }^{30}$ Demirbaş, A. Calculation of higher heating values of biomass fuels. Fuel 1997, 76, 431. [CrossRef]

${ }^{31}$ Mohsenin, N.; Zaske, J. Stress relaxation and energy requirements in compaction of unconsolidated materials. Journal of Agricultural Engineering Research 1976, 21, 197. [CrossRef]

${ }^{32}$ Antwi-Boasiako, C.; Acheampong, B. B. Strength properties and calorific values of sawdust-briquettes as wood-residue energy generation source from tropical hardwoods of different densities. Biomass and Bioenergy 2016, 85, 149. [CrossRef]

${ }^{33}$ Brasil, D. S.; Martins, M. P.; Nakashima, G. T.; Yamaji, F. M. Use of sugarcane bagasse and candeia waste for solid biofuels production. Floresta 2015, 45, 189. [CrossRef]
${ }^{34}$ Kambo, H. S.; Dutta, A. Strength, storage, and combustion characteristics of densified lignocellulosic biomass produced via torrefaction and hydrothermal carbonization. Applied Energy 2014, 135, 188. [CrossRef]

${ }^{35}$ Callister, W. D.; Rethwisch, D. G; Materials science and engineering: an introduction, $7 \mathrm{a}$. ed., Wiley: New York, 2007.

${ }^{36}$ Sítio de Parque Torino. 7 características essenciais de um galpão de armazenamento. Disponível em: <http://goo.gl/QJOSb4>. Acesso em: 26 julho 2016.

${ }^{37}$ Oliveira, J. B.; Vivacqua Filho, A.; Gomes, P. A. Produção de carvão vegetal: aspectos técnicos. Em PENEDO, W.R. (Ed.). Produção e utilização de carvão vegetal; Série de Publicações Técnicas. CETEC: Belo Horizonte, $1982,8,60$. 